\title{
Seasonal shift of dominance in a submerged rooted macrophyte community of Lake Balaton
}

\author{
Viktor R. Tóth and Sándor Herodek \\ Hungarian Academy of Sciences, Balaton Limnological Research Institute, Klebelsberg Kuno út 3., 8237 Tihany, Hungary
}

Received 17 September 2010; Accepted 13 December 2010

\begin{abstract}
Abiotic heterogeneity of the littoral zone of Lake Balaton influences both horizontal and vertical distribution of macrophytes, but biotic differences could shape the nature of a community. Vertical and temporal (small timescale) biomass distributions of Potamogeton perfoliatus and Myriophyllum spicatum were analysed in relation to their photosynthetic capacities to understand their coexistence, general presence over the northern shore of the lake seasonal shift of dominance within the community.

Our results indicated the adaptation of these macrophytes to the rapidly changing and mostly low irradiance of the Lake Balaton originated from its high turbidity: both $P$. perfoliatus and $M$. spicatum had high photosynthetic activity (20 to $50 \mathrm{mg} \mathrm{O}_{2} \cdot \mathrm{g} \mathrm{drw}^{-1} \cdot \mathrm{h}^{-1}$ ), low dark respiration (around 12-14\% of maximal photosynthetic capacity) and high shade tolerance $\left(I_{\mathrm{c}}\right.$ of plants were $29 \pm 18$ and $26 \pm 18 \mu \mathrm{mol}_{\mathrm{m}} \mathrm{m}^{-2}$.s $\mathrm{s}^{-1}$, respectively). The majority of photosynthetic parameters had no (or little) seasonal changes. On the other hand, in Lake Balaton P. perfoliatus and M. spicatum differed in vertical distribution of biomass: Myriophyllum concentrated its biomass in the upper, well-lit region of the water more strongly than the Potamogeton.

Results suggest that the autogenic shift of dominance from Potamogeton to Myriophyllum in Lake Balaton can't be explained only by seasonal patterns of photophysiological changes, but supported by constitutive differences in plants architecture could led to the described phenomena.
\end{abstract}

Key words: Light / biomass distribution / photosynthesis / Potamogeton perfoliatus / Myriophyllum spicatum

\section{Introduction}

Lake Balaton is the largest freshwater lake in Central Europe by surface area $\left(598 \mathrm{~km}^{2}\right)$ and lies in the centre of the Pannonian Basin. Its relative shallowness (average depth $\sim 3.5 \mathrm{~m}$ ) combined with the large surface determines its turbid nature and the highly variable light climate of the lake. The sediment of Lake Balaton (especially on the northern shore) consists mainly of manganese rich calcite of lacustrine origin and together with the prevailing regional northern winds determines the turbid nature of the lake. Thus, Lake Balaton is colonised mostly by submerged macrophytes that could withstand low irradiances.

Potamogeton perfoliatus L. (Potamogetonaceae, clasping-leaf pondweed) and Myriophyllum spicatum L. (Haloragaceae, Eurasian watermilfoil) are two of the most common, stand forming, rooted, submerged macrophytes of Lake Balaton. These macrophytes coexist all

Corresponding authors: donvito@tres.blki.hu, herodek@tres.blki.hu over the littoral zone of the northern shore. At the end of summer, there is a well-distinguished shift of dominance between the two submerged rooted macrophytes: although $P$. perfoliatus is the first to appear, to reach the water surface and to bloom all over the lake, by the end of summer M. spicatum in the major part of the northern shore becomes more dominant and outgrow the pondweed (personal observation).

Propagation and growth of $P$. perfoliatus and $M$. spicatum are affected by a vast number of factors, but availability of light is considered to be one of the most important (Barko et al., 1982; Kemp et al., 1985; Asaeda et al., 2004). Submerged macrophytes typically show low gas exchange rates (both photosynthesis and dark respiration) and low compensation irradiances, but at saturating (optimal) light intensities can produce significantly higher photosynthetic and respiratory rates (Bowes and Salvucci, 1989; Duarte, 1991; Rae et al., 2001). These plants are interacting with each other and other macrophytes, competing for the source of energy and nutrients (Chambers and Prepas, 1990; Abernethy et al., 1996; Agami and Waisel, 2002; Baattrup-Pedersen et al., 2003). 


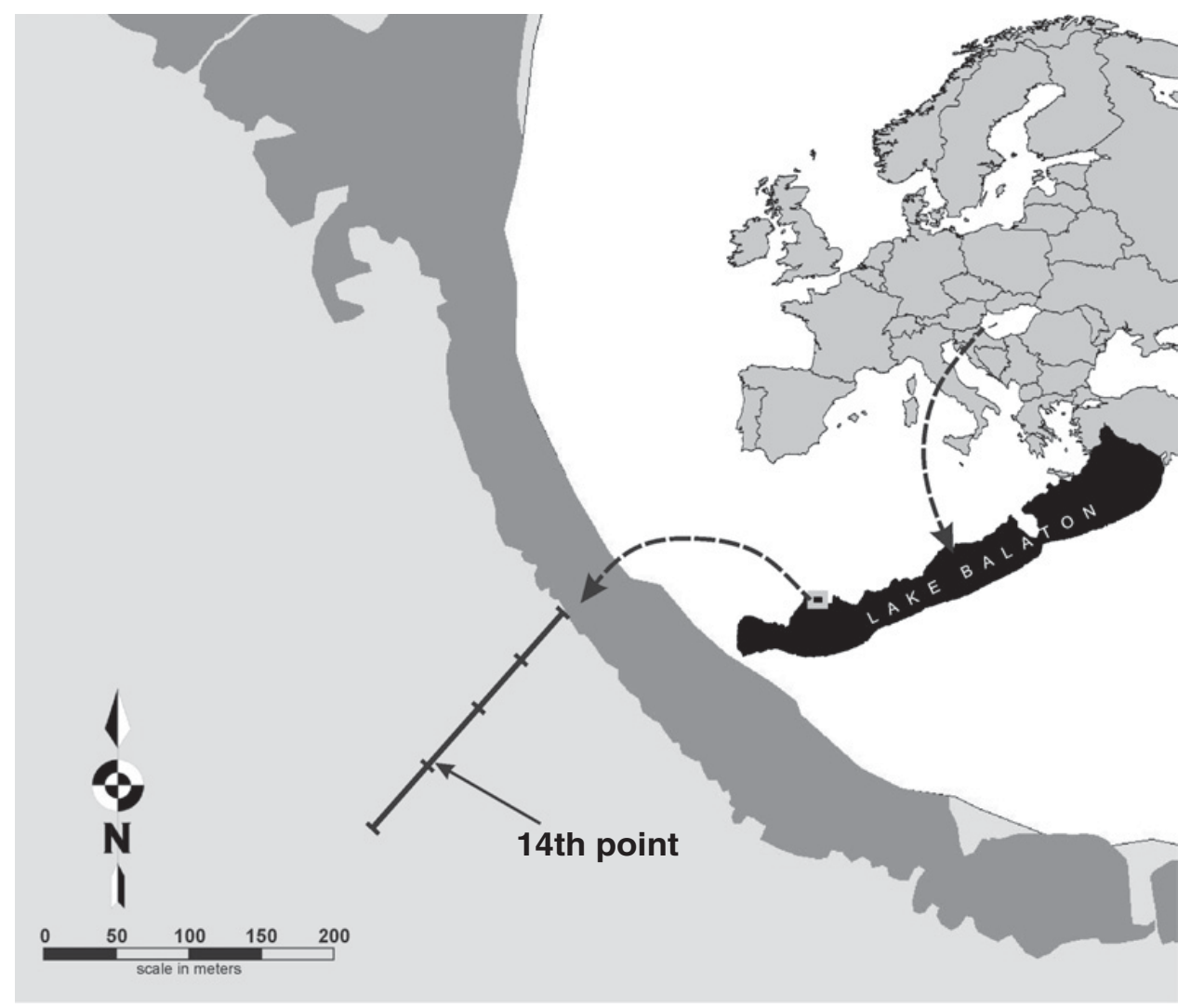

Figure 1. The view on Europe, the Lake Balaton and the delimited area of the sampling site with the transect and 14th sampling point. On the larger map of the sampling site the light grey area presents the open water, while the dark grey area are the reed stands of the Lake Balaton.

Empirical studies on temporal variability of macrophyte communities mainly focused on long-scale dynamics (Fisher et al., 1982; McCreary, 1991) and less on the smallscale temporal patterning (Barrat-Segretain and Amoros, 1996), although the latter might give significantly more information about the coexistence and competition of the studied species. Affinity of an aquatic macrophyte for sources of energy, nutrients and carbon determines its interspecific competitiveness in mixed stands (Agami and Waisel, 1985; Van et al., 1999; Davis and Fourqurean, 2001; Barrat-Segretain, 2004), while the spatial and temporal fluctuations of these affinities determines the spatial patchiness or the temporal succession of the submerged macrophytes at a site (Bonis and Grillas, 2002; Roxburgh et al., 2004).

Little is known about the evolutional and ecological significances of the small time-scale interspecific competition. To understand the interactions within the littoral macrophyte community, the knowledge of seasonal, intrinsic variability in the productivity and biomass distribution of the studied plants is essential. The goal of this study was to evaluate the effect of seasonal variability of photosynthesis on the interspecific competition and success of rooted submerged macrophytes of Lake Balaton. We hypothesized that the seasonal change of photosynthetic parameters trigger the shift from
$P$. perfoliatus to $M$. spicatum-dominated macrophyte stands on the northern shore of Lake Balaton.

\section{Materials and methods}

\section{Sampling site}

For this study a transect in a recreationally nondisturbed area (Szigliget Basin) of Lake Balaton was selected (Fig. 1). This site was chosen because of its typical geomorphology and macrophyte composition. The first point of the transect (N46 47'18.03", E17 $\left.{ }^{\circ} 5^{\prime} 37.28^{\prime \prime}\right)$ was placed in front of a small, $65 \mathrm{~m}$ wide reed bed. The last point of the transect (N46 $\left.47^{\prime} 14.03^{\prime \prime}, \mathrm{E} 17^{\circ} 25^{\prime} 29.87^{\prime \prime}\right)$ was $200 \mathrm{~m} \mathrm{SW}$ of the first one. At five sampling points, evenly distributed along the transect, sediment was analysed for total $\mathrm{P}, \mathrm{N}$ and $\mathrm{K}$ content with no replicates (Table 1). Water temperature and irradiance was monitored at the 14th point of the transect at six depths within the macrophyte stand with pendant temperature and light sensors (Onset Computer Corporation, US) (Table 2). Light attenuation coefficient $\left(K_{\mathrm{d}}, \mathrm{m}^{-1}\right)$ of the whole water column with plants was calculated from the slope of the linear regression of averaged irradiances collected by depth and related to the depth of measurements (Table 2). 
Table 1. Water depth (m), total nitrogen (g. $\left.\mathrm{kg}^{-1}\right)$, total phosphorus (mg. $\mathrm{kg}^{-1}$ ) and total potassium $\left(\mathrm{g} \cdot \mathrm{kg}^{-1}\right)$ content of the sediment in several points of the studied transect.

\begin{tabular}{|c|c|c|c|c|c|}
\hline$\overline{\text { Point number }}$ & 1 & 6 & 11 & 16 & 21 \\
\hline$\overline{\text { From 1st point (m) }}$ & 0 & 50 & 100 & 150 & 200 \\
\hline Water depth (m) & 1.4 & 1.6 & 1.8 & 2.1 & 2.2 \\
\hline Total $\mathrm{N}\left(\mathrm{g} \cdot \mathrm{kg}^{-1}\right)$ & 2.9 & 2.9 & 2.8 & 2.6 & 2.7 \\
\hline Total P (mg.kg $\left.{ }^{-1}\right)$ & 350 & 356 & 305 & 307 & 281 \\
\hline Total K $\left(\mathrm{g} \cdot \mathrm{kg}^{-1}\right)$ & 94 & 68 & 38 & 27 & 38 \\
\hline
\end{tabular}

These measurements were performed during every single sampling (photosynthetic or biomass) event, i.e. 31 times between April and September.

\section{Plant material}

For our experiments clasping-leaf pondweed (Potamogeton perfoliatus L., Potamogetonaceae) and Eurasian watermilfoil (Myriophyllum spicatum L., Haloragaceae) were used.

\section{Photosynthesis measurements}

The photosynthesis measurements of $P$. perfoliatus was studied between the 4th of April and 10th of August for 16 times, while $M$. spicatum's primer productions was determined on nine occasions between 26th of April and 18th of August. The sampling was always performed between 9:00 and 10:00.

Close to the 14th point of the studied transect, at depth of 1.9-2 m, 10-12 intact, healthy looking plants of $P$. perfoliatus and M. spicatum were collected for photosynthesis measurements. The plants were transported within an hour to a laboratory in a darkened cooling box filled with lake water. In the laboratory, 1-2 fully mature, youngest leaves ( $c a .50 \mathrm{~cm}$ from apex) were collected from each plant and were used for photosynthetic measurements (Tóth and Herodek, 2009). In general, 1-2 leaves were placed into each $300 \mathrm{~mL}$ Karlsruhe vial (WTW, Germany) filled with filtered (pore size $0.45 \mu \mathrm{m}$ ) lake water. All 18 Karlsruhe vials (three vials for each irradiance) were placed into an incubation tank specially designed for photosynthesis measurements (Tóth and Herodek, 2009). Fluorescent tubes (F33 Coolwhite, Tungsram, Hungary, correlated colour temperature $4000 \mathrm{~K}$ ) were used as source of light and RE50NEARL Scotchshield ${ }^{(x)}$ Ultra Safety and Security Window film (3M, USA) was used for light quenching (Tóth and Herodek, 2009). The film was applied to different areas of the incubation tank in growing number of layers, thus producing a range of light $(18,43,113,205,408$ and $\left.780 \mu \mathrm{mol} \cdot \mathrm{m}^{-2} \cdot \mathrm{s}^{-1}\right)$. Irradiance was constantly monitored by a spherical irradiance sensor (US-SQS/L, WALZ, Germany) attached to a data logger (LI 1400, LI-COR Biosciences GmbH, Germany). Temperature of photosynthesis was set to the actual water temperature of
Lake Balaton (cooling-heating bath, Neslab RTE-17, Thermo Electron, USA). Mixing was provided by stirring bars and specially made magnetic stirrers (rotation speed $30 \mathrm{rpm}$ ) placed under the incubation tank (Tóth and Herodek, 2009). Prior to measurement, the plants were incubated for $30 \mathrm{~min}$ in darkness in the Karlsruhe vials. Photosynthesis was measured using oxygen electrode (TriOxmatic 300, WTW, Germany) connected to a data logger (Oxi 539 microprocessor precision oxygen meter, WTW, Germany) with 30 min incubation time. Dark respiration was measured with light source switched off for another $30 \mathrm{~min}$. The $\mathrm{pH}$ and DIC of the incubation water was constantly monitored and was replaced after each set of measurements, nevertheless the changes within the Karlsruhe vials never exceeded the $1 \%$. Along the vegetation period the $\mathrm{pH}$ was $8.39 \pm 0.09$ and the DIC was $51.8 \pm 1.0 \mathrm{mg} . \mathrm{L}^{-1}$.

The data obtained from photosynthesis measurements were fitted with a modified exponential saturation model of Platt (Platt et al., 1980): $P=R_{\mathrm{d}}+$ $P_{\mathrm{s}} \cdot\left(1-\mathrm{e}^{-\alpha \cdot I / P_{\mathrm{s}}}\right) \cdot \mathrm{e}^{-\beta \cdot I / P_{\mathrm{s}}}$. The equation contains the following parameters: $P\left(\mathrm{mg} \mathrm{O}_{2} \cdot \mathrm{g} \mathrm{dw}^{-1} \cdot \mathrm{h}^{-1}\right)$ is the photosynthetic activity at the $I$ irradiance $\left(\mu \mathrm{mol} . \mathrm{m}^{-2} . \mathrm{s}^{-1}\right), P_{\mathrm{s}}$ is the actual light saturated photosynthetic activity, $\alpha$ is the photosynthetic, while $\beta$ is the inhibition coefficient and $R_{\mathrm{d}}$ is dark respiration $\left(\mathrm{mg} \mathrm{O}_{2} \cdot \mathrm{g} \mathrm{dw}^{-1} \cdot \mathrm{h}^{-1}\right)$. From the equation above maximal photosynthetic rate $P_{\max }=$ $P_{\mathrm{s}} \cdot(\alpha /[\alpha+\beta]) \cdot(\beta /[\alpha+\beta])^{(\beta / \alpha)}$, theoretical irradiance of saturation photosynthesis $I_{\mathrm{k}}=P_{\max } / \alpha$, compensation irradiance $I_{\mathrm{c}}=\left(P_{\mathrm{s}} \cdot\left[-\ln \left(1-R_{\mathrm{d}} / P_{\mathrm{s}}\right)\right]\right) /(\alpha+\beta)$, and irradiance of light inhibition of photosynthesis $I_{\mathrm{b}}=P_{\mathrm{s}} / \beta$ were calculated.

To estimate the water depth where the light reaches the compensation $\left(I_{\mathrm{c}}\right)$ or the theoretical saturation $\left(I_{\mathrm{k}}\right)$ irradiances transformed Lambert-Beer equation $\left(I_{\mathrm{z}}=I_{0} \cdot \mathrm{e}^{-K_{\mathrm{d}} \cdot \mathrm{z}}\right)$ was used: $Z_{\mathrm{c}}=-\frac{\ln \left(I_{\mathrm{c}} / I_{0}\right)}{K_{\mathrm{d}}}$ and $Z_{\mathrm{k}}=-\frac{\ln \left(I_{\mathrm{k}} / I_{0}\right)}{K_{\mathrm{d}}}$ where $K_{\mathrm{d}}$ is the light attenuation coefficient $\left(\mathrm{m}^{-1}\right),{ }^{K_{\mathrm{d}}} Z_{\mathrm{c}}$ is maximum depth of colonization, $Z_{\mathrm{k}}$ is the light saturation depth, while $I_{0}$ is the inherent irradiance.

\section{Cover and biomass}

Abundance of macrophytes along the transect at the pre-determined points was quantified by visual estimation (cover \%) within the whole water column under a floating $1 \mathrm{~m}^{2}$ quadrant. The abundance of plants was monitored each month from May to September.

In the close proximity (within $2 \mathrm{~m}$ ) of the 14th sampling point of the transect at the depth of 1.9-2 m, in an area with the same species composition, density and water depth, plants for biomass were sampled once a month at the day of cover estimation. A sampling quadrant $\left(0.25 \mathrm{~m}^{2}\right)$ fitted with a $2 \mathrm{~m}$-long net was lowered to the lake bottom. Following its underwater assemblage, all macrophytes trapped within the net were pulled out of the sediment, later rinsed to remove sediment and periphyton. Plant biomass was sorted by species and optical regions, i.e. part of biomass situated within the water 
Table 2. Temperature $\left(T,{ }^{\circ} \mathrm{C}\right)$ and irradiance $\left(I, \mu \mathrm{mol} . \mathrm{m}^{-2} \cdot \mathrm{s}^{-1}\right)$ within the water column of the 14 th point of the transect.

\begin{tabular}{|c|c|c|c|c|c|c|c|c|}
\hline \multirow{2}{*}{ Depth $(\mathrm{cm})$} & \multicolumn{2}{|c|}{$14 / 5$} & \multicolumn{2}{|c|}{$17 / 6$} & \multicolumn{2}{|c|}{$15 / 7$} & \multicolumn{2}{|c|}{$14 / 8$} \\
\hline & $T$ & $I$ & $T$ & $I$ & $T$ & $I$ & $T$ & $I$ \\
\hline 0 & 18.1 & 1847 & 22.8 & 2041 & 24.0 & 2130 & 23.4 & 1932 \\
\hline-20 & 18.4 & 1694 & 20.9 & 1541 & 23.0 & 1315 & 22.6 & 1036 \\
\hline-40 & 17.5 & 611 & 20.0 & 582 & 22.1 & 442 & 21.1 & 565 \\
\hline-80 & 17.0 & 367 & 19.6 & 373 & 21.4 & 169 & 20.8 & 361 \\
\hline-160 & 16.8 & 158 & 19.1 & 164 & 21.1 & 54 & 20.3 & 135 \\
\hline-200 & 15.8 & 60 & 18.2 & 60 & 20.9 & 15 & 19.4 & 46 \\
\hline
\end{tabular}

column in a region of special optical environment. The optical regions of the water column were defined as following: minimal - water levels with irradiances lower than $I_{\mathrm{c}}$ (from sediment till $Z_{\mathrm{c}}$, see above), suboptimal-where the irradiance is between $I_{\mathrm{c}}$ and $I_{\mathrm{k}}$ and optimal - where the irradiance is higher than $I_{\mathrm{k}}$ (from the surface of the water till $Z_{\mathrm{k}}$, see above). For each biomass portioning the $K_{\mathrm{d}}$ at the time of biomass sampling and the closest measured $I_{\mathrm{k}}$ and $I_{\mathrm{c}}$ results were used. In laboratory, partly dehydrate macrophytes were cut and grouped into these regions. These biomass portions were oven-dried (Heraeus T6, Heraeus, USA; at $105^{\circ} \mathrm{C}$ for $72 \mathrm{~h}$ ), weighted (OHAUS Explorer, Ohaus Corp., USA) and expressed as grams of dry weight per unit surface area.

\section{Mathematical and statistical analysis}

The photosynthesis data were fitted with exponential saturation model (Platt et al., 1980), total macrophyte biomass data were fitted with a Gaussian, four parameter function $\left(y=y_{0}+a \mathrm{e}^{\left[-0.5\left(\left(x-x_{0}\right) / b\right)^{2}\right]}\right)$. Both fits were made using the least-squares technique. For graphing the results, curve fitting and analysis Sigma Plot v 8.0 (Systat Software Inc., USA) was used. For all curves fitted ANOVA was performed (all $P<0.02$ and $R^{2}>0.92$ ). Linear correlation of data was made by RExcel statistical analysis software v.3.0.17 (Baier and Neuwirth, 2007). Assumptions of normality and homoscedascity were determined and, when necessary, data were transformed to attain a normal distribution.

\section{Results}

\section{Study area}

At the studied transect the water depth showed steady increase from $1.4 \mathrm{~m}$ up to $2.2 \mathrm{~m}$ at the last point of the transect (Table 1). The character of the sediment throughout the transect was predominantly homogeneous, loose, siliceous calcite-dolomite sediment. There was no observable nutrient deficiency in the studied plants, the total nitrogen was $2.78 \pm 0.06$ g. $\mathrm{kg}^{-1}$, total $\mathrm{P}$ was $320 \pm 14 \mathrm{mg} \cdot \mathrm{kg}^{-1}$, total K was $53 \pm 12 \mathrm{~g} \cdot \mathrm{kg}^{-1}$ (Table 1).

Table 2 shows the temperature and irradiance at different depth within the water column of the photosynthesis sampling point on four occasions of the vegetative period.
In general, the light attenuation coefficients at the sampling point during May, June, July and August (measured of several occasions, average $\pm \mathrm{SD}$ ) was $1.89 \pm 0.95$, $2.02 \pm 0.79,2.57 \pm 0.69$ and $2.22 \pm 0.66 \mathrm{~m}^{-1}$, respectively.

\section{Macrophyte growth and biomass accumulation}

At the studied site, both $P$. perfoliatus and $M$. spicatum were present during each of the six sampling events. $P$. perfoliatus was most abundant $(\sim 35 \%)$ in the shallow water part of the transect (Fig. 2A). At this side of the transect the cover peaked in end of June, while at deeper parts of the transect the cover was smaller $(\sim 10 \%)$ and reached its maximum later (end of July, August) (Fig. 2A). On the other hand M. spicatum reached the peak of its abundance also at the shallow part of the transect $(\sim 38 \%)$, but slightly later than $P$. perfoliatus, i.e. at the beginning of August (Fig. 2A). Starting from late June there were both $P$. perfoliatus and M. spicatum in the deeper (over $1.8 \mathrm{~m}$ ) water, but with clear and obvious aggregation into well separated small colonies (Fig. 2).

Close to the 14th sampling point of the transect plants for biomass analysis were collected. On the first sampling date $P$. perfoliatus and $M$. spicatum plants were small (under $60 \mathrm{~cm}$ ), the dry biomass of the plants reached 43 and 24 g.m ${ }^{-2}$, respectively (Fig. 2). In June the biomass of $P$. perfoliatus doubled, while the biomass of $M$. spicatum nearly tripled (Fig. 2). The sampled biomass of $P$. perfoliatus reached its maximum at the end of June and topped at $155 \mathrm{~g} \mathrm{drw.m}{ }^{-2}$ (Fig. 2B). In July and August the biomass of $P$. perfoliatus gradually decreased to $58 \mathrm{~g}$ drw. ${ }^{-2}$, and in the cold water of the September nearly vanished (data not shown). The $M$. spicatum reached its seasonal maximum of biomass in July $\left(146 \mathrm{~g}\right.$ drw. $\left.{ }^{-2}\right)$, but throughout summer the plant biomass showed little variation (under 5\%). The fitted 4-parameter Gaussian function positioned the apex of the curves for $P$. perfoliatus on 4 th of July at theoretical maximum biomass of $125 \mathrm{~g}$ drw.m ${ }^{-2}$ (Fig. 2B, solid line), while $M$. spicatum topped on the 24th of July with biomass of $159 \mathrm{~g} \mathrm{drw.m}{ }^{-2}$ (Fig. 2B, dotted line).

\section{Photosynthesis}

The photosynthesis light response curves were typical, characterizing the underlying photophysiological 


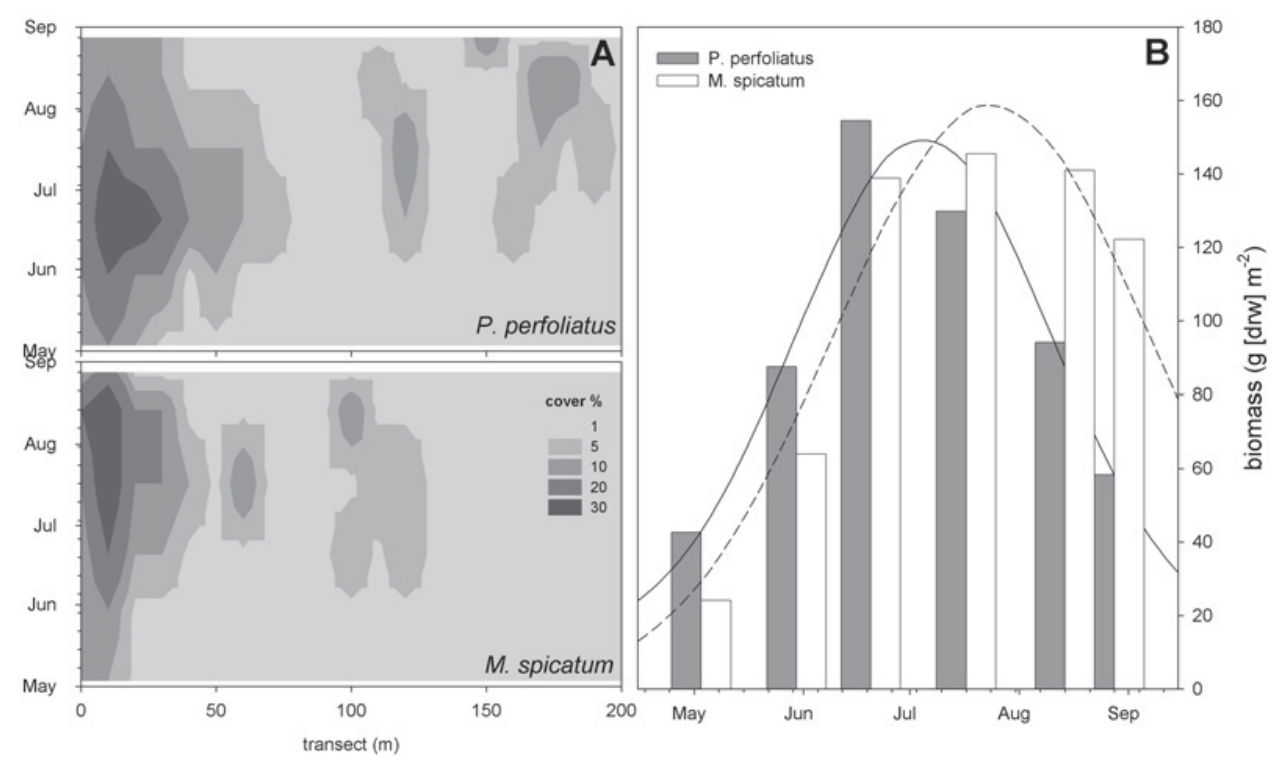

Figure 2. A. Cover (\%) of Potamogeton perfoliatus and Myriophyllum spicatum estimated by visual observation on 21 points of a $200 \mathrm{~m}$ transect. B. Biomass (g drw. $\mathrm{m}^{-2}$ ) of Potamogeton perfoliatus (grey bars, solid line) and Myriophyllum spicatum (white bars, dotted line) at the 14th point of the transect. The presented lines are two dimensional four parameter Gaussians fits to the subsets of data.

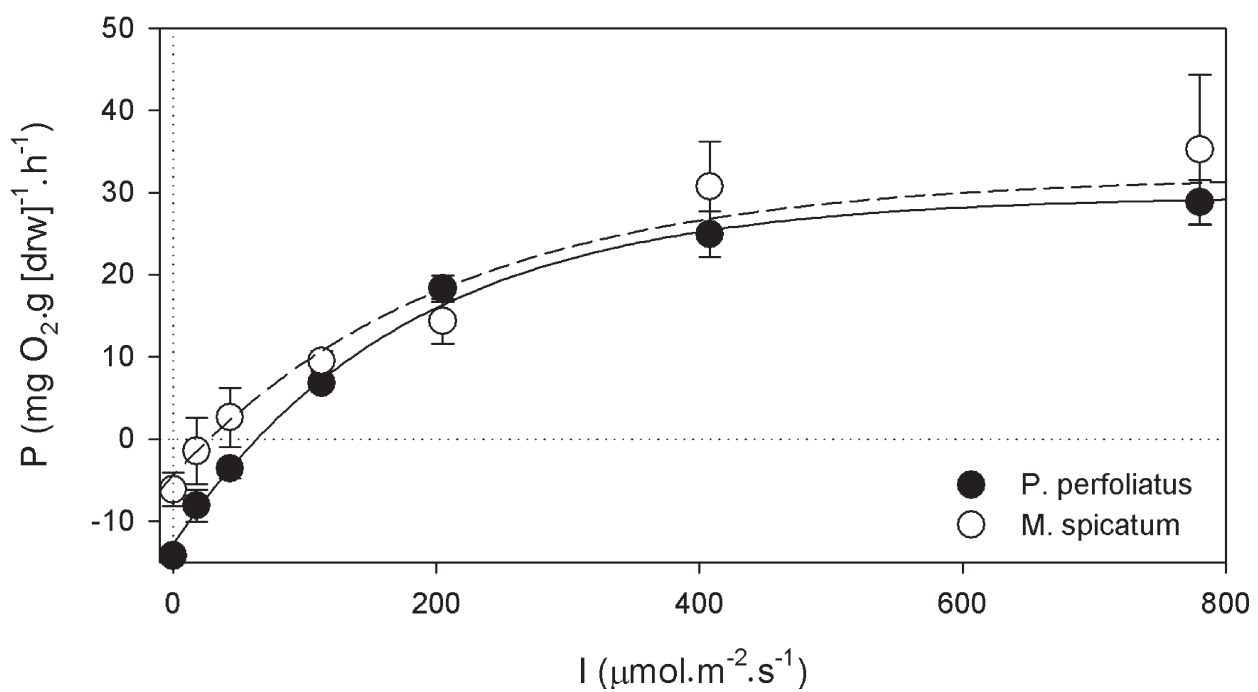

Figure 3. Photosynthesis of Potamogeton perfoliatus (black symbol) and Myriophyllum spicatum (white symbols) at different light intensities. Each symbol is average $\pm \mathrm{SD}(n=3)$. The presented lines are fitted exponential saturation equation (Platt et al., 1980). The $\mathrm{R}^{2}$ of the fits are 0.995 and 0.969 , the results of analysis of variance are $F=438.7, P<0.001$ and $F=64.5, P<0.001$ for $P$. perfoliatus and $M$. spicatum respectively.

processes, that is the efficiency of light utilisation and $\mathrm{CO}_{2}$ uptake of macrophytes (Fig. 3). Based upon each set of photosynthesis data, light saturation curves were fitted (see Materials and methods) and here the most important photosynthetic parameters are discussed.

The maximal intensity of photosynthesis $\left(P_{\max }\right)$ of $P$. perfoliatus during the vegetation period changed between 12.1 and $46.2 \mathrm{mg} \mathrm{O}_{2} \cdot \mathrm{g} \mathrm{drw}^{-1} \cdot \mathrm{h}^{-1}$ and showed strong, positive correlation with the date of experiment (Fig. 4, Table 3). The intensity of dark respiration $\left(R_{\mathrm{d}}\right)$ decreased during the season from 24.6 in spring to 1.4 $4.1 \mathrm{mg} \mathrm{O}_{2} . \mathrm{g} \mathrm{drw}^{-1} \cdot \mathrm{h}^{-1}$ by the end of summer (Fig. 4,
Table 3). Compensation irradiance $\left(I_{\mathrm{c}}\right)$ of $P$. perfoliatus during the vegetation period changed between 10 and $44 \mu \mathrm{mol} . \mathrm{m}^{-2} . \mathrm{s}^{-1}$ with no temporal correlation (Fig. 4, Table 1). With progression of the vegetation period the theoretical saturation irradiance $\left(I_{\mathrm{k}}\right)$ of $P$. perfoliatus significantly increased from 30 and $214 \mu \mathrm{mol} \cdot \mathrm{m}^{-2} \cdot \mathrm{s}^{-1}$ (Fig. 4, Table 3).

Only the saturation irradiance of $M$. spicatum increased during the season from 34 to $257 \mu \mathrm{mol} . \mathrm{m}^{-2} . \mathrm{s}^{-1}$, showing a positive seasonal $(R=0.82, P<0.01)$ correlation (Fig. 4, Table 3), while $P_{\max }, R_{\mathrm{d}}$ and $I_{\mathrm{c}}$ of milfoil plants showed high variation during the vegetation period, 


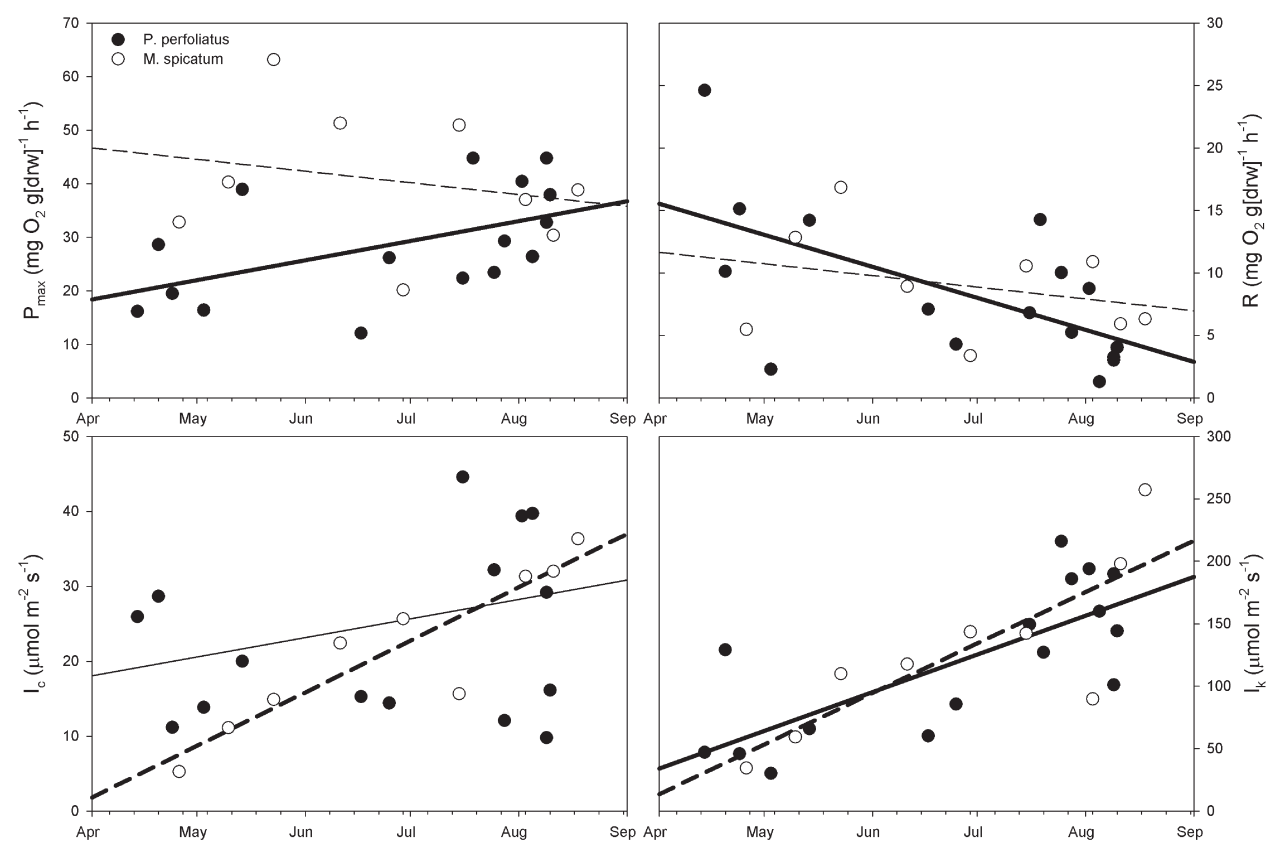

Figure 4. Maximal photosynthetic intensity $\left(P_{\max }-\mathrm{mg} \mathrm{O}_{2} \cdot \mathrm{g} \mathrm{drw}{ }^{-1} \cdot \mathrm{h}^{-1}\right)$, dark respiration $\left(R-\mathrm{mg} \mathrm{O}_{2} \cdot \mathrm{g} \mathrm{drw}^{-1} \cdot \mathrm{h}^{-1}\right)$, compensation irradiance $\left(I_{\mathrm{c}}-\mu \mathrm{mol} . \mathrm{m}^{-2} \cdot \mathrm{s}^{-1}\right)$ and theoretical saturation irradiance $\left(I_{\mathrm{k}}-\mu \mathrm{mol} . \mathrm{m}^{-2} . \mathrm{s}^{-1}\right)$ of Potamogeton perfoliatus (closed symbols, solid line) and Myriophyllum spicatum (open symbols, dashed lines) during the vegetation period on the northern shoreline of Lake Balaton. Bolder lines show the significant correlations.

thus the data had no recognisable seasonal tendency (Fig. 4, Table 3).

\section{Depth distribution}

Based on result of photosynthesis measurements, the seasonal change incident irradiance (Table 2) and the light attenuation within the water column (Table 2), light saturation depth $\left(Z_{\mathrm{k}}\right)$ and maximum depth of colonization $\left(Z_{\mathrm{c}}\right)$ of $P$. perfoliatus and $M$. spicatum were calculated. The light saturation depth of $P$. perfoliatus and M. spicatum plants showed high variability during the vegetation period significantly decreasing from $1.3-1.7 \mathrm{~m}$ in the spring to $0.4-0.9 \mathrm{~m}$ in the end of summer (Fig. 5, Table 3). During the time span studied, the maximum depth of colonization $\left(Z_{\mathrm{c}}\right)$ of $P$. perfoliatus had no recognisable seasonal pattern, changing between 1.2 and $2.4 \mathrm{~m}$, while $Z_{\mathrm{c}}$ of $M$. spicatum had strong, negative and significant correlation with the date of sampling (Fig. 5, Table 3). In the beginning of the vegetation period, the maximum depth of colonization of $M$. spicatum plants was lower than the $Z_{\mathrm{c}}$ of the P. perfoliatus (2.2-2.7 and $1.7-2.3 \mathrm{~m}$, respectively), but by the end of July (two lines are crossed at 07.12 . and $1.9 \mathrm{~m}$ ) the average $Z_{\mathrm{c}}$ of milfoil became higher $(1.2-1.7 \mathrm{~m}$ as compared to the 1.2-2.4 depth of P.perfoliatus) (Fig. 5).

The layer within the water column of $P$. perfoliatus specific suboptimal irradiance $\left(Z_{\mathrm{c}}<I_{\mathrm{so}}<Z_{\mathrm{k}}\right)$ gradually increased during the season (from $0.4-0.8$ to $1.1-1.4 \mathrm{~m}$ ), while in the case of $M$. spicatum the region stayed literally unchanged throughout the summer $(1.0 \pm 0.2 \mathrm{~m})$
Table 3. Linear correlation of maximal photosynthetic intensity $\left(P_{\max }-\mathrm{mg} \mathrm{O}_{2} \cdot \mathrm{g} \mathrm{drw}^{-1} \cdot \mathrm{h}^{-1}\right)$, dark respiration $\left(R-\mathrm{mg} \mathrm{O}_{2} \cdot \mathrm{g}\right.$ $\left.\mathrm{drw}^{-1} \cdot \mathrm{h}^{-1}\right)$, compensation irradiance $\left(I_{\mathrm{c}}-\mu \mathrm{mol} \cdot \mathrm{m}^{-2} \cdot \mathrm{s}^{-1}\right)$, theoretical saturation irradiance $\left(I_{\mathrm{k}}-\mu \mathrm{mol} \cdot \mathrm{m}^{-2} \cdot \mathrm{s}^{-1}\right)$, maximum depth of colonization $\left(Z_{\mathrm{c}}-\mathrm{m}\right)$ and light saturation depth $\left(Z_{\mathrm{k}}-\mathrm{m}\right)$ of Potamogeton perfoliatus and Myriophyllum spicatum to date of sampling. Significance of correlation: ns, $P>0.05 ; *, P \leq 0.05 ; * *, P \leq 0.01 ; * * *, P \leq 0.001$. Number of replicates: for Potamogeton $n=16$, for Myriophyllum $n=9$.

\begin{tabular}{lcc}
\hline & $P$. perfoliatus & M. spicatum \\
\hline$P_{\max }$ & $0.52^{*}$ & $-0.29^{\mathrm{ns}}$ \\
$R$ & $-0.55^{*}$ & $-0.09^{\mathrm{ns}}$ \\
$I_{\mathrm{c}}$ & $0.26^{\mathrm{ns}}$ & $0.66^{\mathrm{ns}}$ \\
$I_{\mathrm{k}}$ & $0.75^{* * *}$ & $0.82^{* *}$ \\
$Z_{\mathrm{k}}$ & $0.73^{* *}$ & $0.86^{* *}$ \\
$Z_{\mathrm{c}}$ & $0.11^{\mathrm{ns}}$ & $0.89^{* *}$ \\
$Z_{\mathrm{k}}-Z_{\mathrm{c}}$ & $0.70^{* *}$ & $-0.44^{\mathrm{ns}}$ \\
\hline
\end{tabular}

(Table 1), and by the end of the summer became smaller than in $P$. perfoliatus plants (regression lines crossed at date of 07.15. and at a depth difference of $1 \mathrm{~m}$ ) (Fig. 5).

\section{Biomass partitioning and production}

Using data of $Z_{\mathrm{c}}$ and $Z_{\mathrm{k}}$ we separated biomass of macrophytes into plant parts grown under minimal (biomass situated at greater then $Z_{\mathrm{c}}$ depth), suboptimal (fraction of plant between $Z_{\mathrm{c}}$ and $Z_{\mathrm{k}}$ depths), and supraoptimal (biomass portion over $Z_{\mathrm{k}}$ depth) irradiances (Fig. 6). At the first sampling date whole plant biomass 


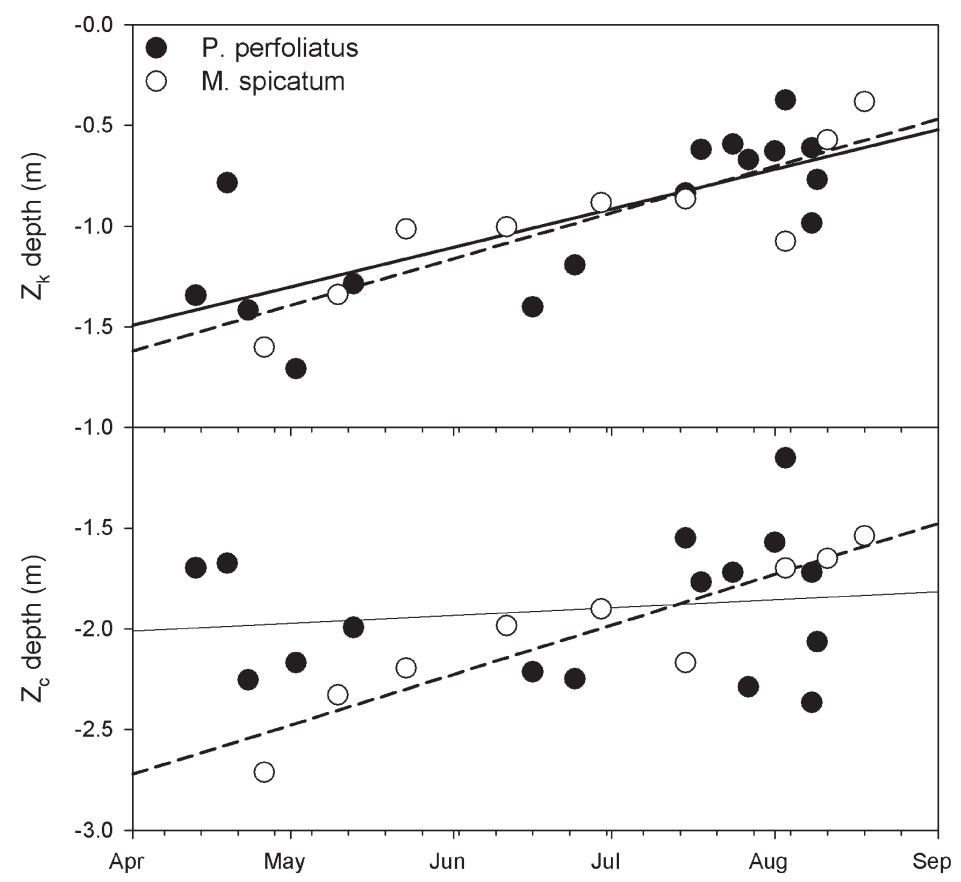

Figure 5. Seasonal variation of maximum depth of colonization $\left(Z_{\mathrm{c}}\right)$ and light saturation depth $\left(Z_{\mathrm{k}}\right)$ of Potamogeton perfoliatus (closed symbols) and Myriophyllum spicatum (open symbols) in Lake Balaton.

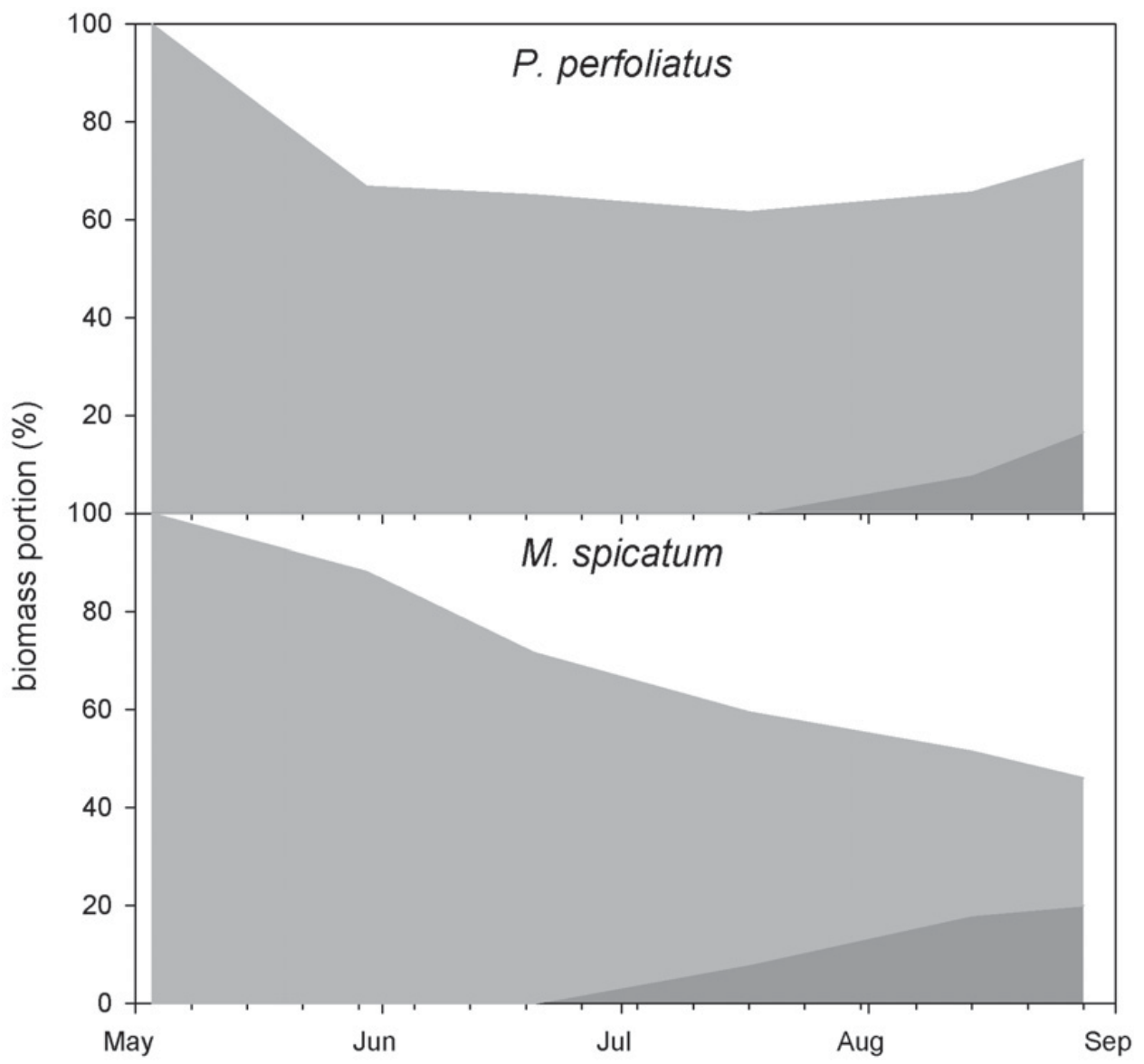

Figure 6. Biomass portion of Potamogeton perfoliatus and Myriophyllum spicatum grown under minimal (dark grey areas), at suboptimal (light grey areas) and at supraoptimal irradiances (white areas). 


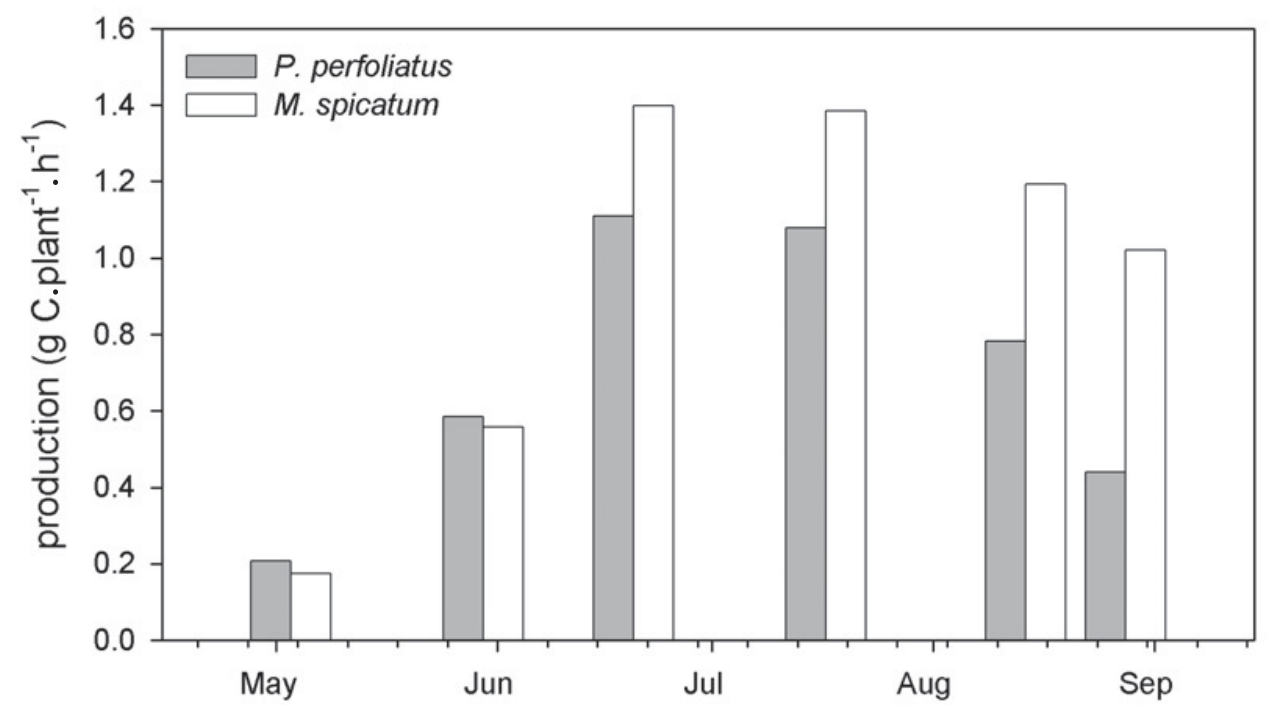

Figure 7. Production of Potamogeton perfoliatus (grey bars) and Myriophyllum spicatum (white bars) along the vegetation period in Lake Balaton estimated from vertical biomass distribution and photosynthesis data.

of $P$. perfoliatus and M. spicatum situated in the suboptimal, but over the minimal required irradiance (Fig. 6). First, at the end of May the upper $33 \%$ of the $P$. perfoliatus and the upper $18 \%$ of the $M$. spicatum grew into the zone of supraoptimal irradiance. For the following five sampling periods, the proportion of $P$. perfoliatus in this supraoptimal light environment stayed literally unchanged $(35,38,34,27 \%)$. On the other hand, M. spicatum constantly increased the fraction of its biomass in the upper, light-saturated part of the water column, gradually reaching 54\% at the end of summer (Fig. 6, white areas).

Production of $P$. perfoliatus and $M$. spicatum estimated on the basis of maximal photosynthesis, dark respiration (Fig. 4), and the vertical distribution of plant biomass (Fig. 6) showed that pondweed exceeded watermilfoil only in the beginning of the vegetation period and the difference was only marginal (Fig. 7). Starting in June, the production of M. spicatum was higher and by the end of summer this difference exceeded $50 \%$ (Fig. 7).

\section{Discussion}

Potamogeton perfoliatus and Myriophyllum spicatum are able to coexist in temperate lakes, moreover in Lake Balaton they are the major stand-forming species. Although these macrophytes are found all over the littoral zone of the lake, in all basins, they develop extensive, mixed beds only on the northern shore, while on the southern shore there is no significant tendency of mixing.

As a response to potentially limiting transparency of the water of Lake Balaton (Table 2), P. perfoliatus and $M$. spicatum show photosynthetic features similar to those found in shade leaves of terrestrial plants (Bowes and Salvucci, 1989; Dring, 1991), i.e. low compensation and saturation irradiance and high photosynthetic rates at saturating light (Fig. 4) (Caffrey and Kemp, 1991; Harley and Findlay, 1994). The measured parameters for both macrophytes were higher than previously published (Titus and Stone, 1982; Goldsborough and Kemp, 1988; Harley and Findlay, 1994), but within the acceptable range. On the basis of these data it may be stated, that these species occupy the same virtual place (niche) in the macrophyte community and compete for the same source of energy, light. Although we hypothesized that coexistence of $P$. perfoliatus and $M$. spicatum in Lake Balaton could be affected by seasonal fluctuations of photosynthetic parameters, the observed differences alone are not sufficient to initiate the described shift of dominance. Thus, the effect of photosynthesis of the interacting species could have significant effect only when combined with the macrophyte's growth form, i.e. the vertical distribution of the biomass.

Both macrophytes appear in the lake in significant biomass in April, since a lot of M. spicatum plants (and some of $P$. perfoliatus) overwinter under the ice. In spring and early summer Myriophyllum is outgrown by $P$. perfoliatus (Fig. 2B), but this tendency in the middle of the summer is reversed due to the tripling of $M$. spicatum's versus doubling of $P$. perfoliatus's biomass (Fig. 2B). This phenomenon happens mainly due to extensification of growth, increase of biomass in a specific region, i.e. elongation and branching of already present macrophytes (increase of biomass proportion in the upper water levels) and not by appearance of new shoots (increase of biomass proportion in the lower water levels) (Fig. 6).

Although at the end of the summer submerged macrophytes (especially $P$. perfoliatus) are consumed mostly by waterfowl (ducks, swans and coots), fishes (grass carp) and some invertebrates (insect larvae and snails), in general grazers in Lake Balaton have no major impact on decrease of $P$. perfoliatus biomass, and carry only the local importance. Nevertheless, by the end of the summer, the main cause of the biomass decrease in $P$. perfoliatus seen on Figure 2B could be the (intra- and interspecific) 
shading: the majority of basal leaves after loosing their green colour, decay while being still attached to the stem. Thus, starting in the end of July-beginning of August senescence of $P$. perfoliatus and the increased dominance of M. spicatum is regulated by correlating internal (photosynthetic parameters) and abiotic (light and temperature) factors.

Seasonal changes in biomass showed a relatively low maximum biomass density both for $P$. perfoliatus and M. spicatum (Fig. 2B), indicating the far from ideal conditions for growth. The maximum biomass density is one magnitude lower than was previously measured at the same site (personal observation). Although several environmental factors could be responsible for the lower biomass, we observed no nutrient deficiency at the site of the experiments (Table 1).

When the size of plant exceeds the boundary of an environmental factor the overall phenotypic integrity is disrupted and significant intraspecific variability occurs (Bassow and Bazzaz, 1997; Gutschick, 1999; Torres Boeger and Poulson, 2003). Despite the well established assumption that both $P$. perfoliatus and $M$. spicatum are shade-tolerant plants, our results show that only by the end of summer and only the basal part of these macrophytes were located at depth with minimal, i.e. lower than light compensation irradiances (Fig. 6). Moreover, in August half of watermilfoil's biomass concentrated at the upper part of water column with optimal light intensities (over $I_{\mathrm{k}}$ ), while the ratio of biomass of $P$. perfoliatus in this region was significantly lower (Fig. 6). This extensive growth of $M$. spicatum in the upper, well-lit part of the water column increases the light exposure and shades the competitors which consequently results in deterioration of basal leaves of $P$. perfoliatus plants. Such extensive architectural alteration supported by even a minor photophysiological difference (Fig. 4) increased the productivity of Myriophyllum over Potamogeton (Fig. 7), and could be the cause of the visible shift of dominance from $P$. perfoliatus to $M$. spicatum.

Vertical pattern of biomass distribution is already recognized as an important factor in competition of aquatic macrophytes (Duarte and Kalf, 1986; McCreary, 1991), and played a significant role in the shift of dominance between the two studied macrophytes. Although there are observations that indicated the low growth rate of $M$. spicatum compared to $P$. perfoliatus (Titus and Adams, 1979; Madsen et al., 1991; Cenzato and Ganf, 2001), in our results it seems to be only a seasonal phenomena, since at a certain stage of their coexistence the M. spicatum outgrew P. perfoliatus (Fig. 2). Moreover, the increase of the milfoil biomass was a result of intensive branching in the upper part of water column, with optimal (saturation) light conditions.

\section{Conclusion}

Minor seasonal modifications of otherwise conservative photosynthetic apparatus of Potamogeton perfoliatus and Myriophyllum spicatum were observed in the Lake Balaton which could not be correlated with the observed shift of dominance in the macrophyte associations of Lake Balaton on itself. The more plastic, autogen seasonal tendency of $M$. spicatum's biomass accumulation supported by the changes in the photosynthetic apparatus resulted in the increasing abundance of the Myriophyllum plants in the end of summer. The strategies of submerged macrophytes overcoming the low irradiance of the lake are different, too: $P$. perfoliatus rise above low-light depth by higher initial (springtime) growth rates reaching water surface earlier than milfoil, while $M$. spicatum growing more slowly, but concentrating its biomass at the most illuminated part of the water column. Thus, photosynthetic and architectural differences between the studied plants together determine the performance and consecutively the coexistence of Potamogeton perfoliatus and Myriophyllum spicatum in Lake Balaton.

Acknowledgements. This project was supported by the Hungarian National Office for Research and Technology (3B/ 022/2004 BALÖKO). The authors wish to thank Prof. Taras K. Oleksyk for help with editing the manuscript.

\section{References}

Abernethy V.J., Sabbatini M.R. and Murphy K.J., 1996. Response of Elodea canadensis Michx, and Myriophyllum spicatum L. to shade, cutting and competition in experimental culture. Hydrobiologia, 340, 219-224.

Agami M. and Waisel Y., 1985. Inter-relationships between Najas marina L. and three other species of aquatic macrophytes. Hydrobiologia, 126, 169-173.

Agami M. and Waisel Y., 2002. Competitive relationships between two water plant species: Najas marina L. and Myriophyllum spicatum L. Hydrobiologia, 482, 197-200.

Asaeda T., Sultana M., Manatunge J. and Fujino T., 2004. The effect of epiphytic algae on the growth and production of Potamogeton perfoliatus L. in two light conditions. Environ. Exp. Bot., 52, 225-238.

Baattrup-Pedersen A., Larsen S.E. and Riis T., 2003. Composition and richness of macrophyte communities in small Danish streams-influence of environmental factors and weed cutting. Hydrobiologia, 495, 171-179.

Baier T. and Neuwirth E., 2007. Excel :: COM :: R. Computation. Stat., 22, 91-108.

Barko J., Hardin D.G. and Matthews M.S., 1982. Growth and morphology of submersed freshwater macrophytes in relation to light and temperature. Can. J. Bot., 60, 877-887.

Barrat-Segretain M.H., 2004. Growth of Elodea canadensis and Elodea nuttallii in monocultures and mixture under different light and nutrient conditions. Arch. Hydrobiol., 161, 133-144.

Barrat-Segretain M.H. and Amoros C., 1996. Recolonization of cleared riverine macrophyte patches: importance of the border effect. J. Veg. Sci., 7, 769-776.

Bassow S.L. and Bazzaz F.A., 1997. Intra-and inter-specific variation in canopy photosynthesis in a mixed deciduous forest. Oecologia, 109, 507-515. 
Bonis A. and Grillas P., 2002. Deposition, germination and spatio-temporal patterns of charophyte propagule banks: a review. Aquat. Bot., 72, 235-248.

Bowes G. and Salvucci M.E., 1989. Plasticity in the photosynthetic carbon metabolism of submersed aquatic macrophytes. Aquat. Bot., 34, 233-266.

Caffrey J.M. and Kemp W.M., 1991. Seasonal and spatial patterns of oxygen production, respiration and root-rhizome release in Potamogeton perfoliatus L. and Zostera marina L. Aquat. Bot., 40, 109-128.

Cenzato D. and Ganf G., 2001. A comparison of growth responses between two species of Potamogeton with contrasting canopy architecture. Aquat. Bot., 70, 53-66.

Chambers P. and Prepas E., 1990. Competition and coexistence in submerged aquatic plant communities: the effects of species interactions versus abiotic factors. Freshwater Biol., 23, 541-550.

Davis B.C. and Fourqurean J.W., 2001. Competition between the tropical alga, Halimeda incrassata, and the seagrass, Thalassia testudinum. Aquat. Bot., 71, 217-232.

Dring M.J., 1991. The biology of marine plants, Cambridge University Press.

Duarte C.M., 1991. Seagrass depth limits. Aquat. Bot., 40, 363-377.

Duarte C.M. and Kalf J., 1986. Littoral slope as a predictor of the maximum biomass of submerged macrophyte communities. Limnol. Oceanogr., 31, 1072-1080.

Fisher S.G., Gray L.J., Grimm N.B. and Busch D.E., 1982. Temporal succession in a desert stream ecosystem following flash flooding. Ecol. Monogr., 52, 93-110.

Goldsborough W.J. and Kemp W.M., 1988. Light responses of a submersed macrophyte: implications for survival in turbid tidal waters. Ecology, 69, 1775-1786.

Gutschick V., 1999. Biotic and abiotic consequences of differences in leaf structure. New Phytol., 143, 3-18.

Harley M.T. and Findlay S., 1994. Photosynthesis-irradiance relationships for three species of submersed macrophytes in the tidal freshwater Hudson River. Estuar. Coasts, 17, 200-205.
Kemp W.M., Boynton W.R., Cunningham J.J., Stevenson J.C., Jones T.W. and Means J.C., 1985. Effects of atrazine and linuron on photosynthesis and growth of the macrophytes, Potamogeton perfoliatus L. and Myriophyllum spicatum L. in an estuarine environment. Mar. Environ. Res., 16, 255-280.

Madsen J.D., Hartleb C.F. and Boylen C.W., 1991. Photosynthetic characteristics of Myriophyllum spicatum and six submersed aquatic macrophyte species native to Lake George, New York. Freshwater Biol., 26, 233-240.

McCreary N.J., 1991. Competition as a mechanism of submersed macrophyte community structure. Aquat. Bot., 41, 177-193.

Platt T., Gallegos C.L. and Harrison W.G., 1980. Photoinhibition of photosynthesis in natural assemblages of marine phytoplankton. J. Mar. Res., 38, 687-701.

Rae R., Hanelt D. and Hawes I., 2001. Sensitivity of freshwater macrophytes to UV radiation. Mar. Freshwater Res., 52, 1023-1032.

Roxburgh S.H., Shea K. and Wilson J.B., 2004. The intermediate disturbance hypothesis: patch dynamics and mechanisms of species coexistence. Ecology, 85, 359-371.

Titus J.E. and Adams M.S., 1979. Coexistence and the comparative light relations of the submersed macrophytes Myriophyllum spicatum L. and Vallisneria americana Michx. Oecologia, 40, 273-286.

Titus J.E. and Stone W.H., 1982. Photosynthetic response of two submersed macrophytes to dissolved inorganic carbon concentration and $\mathrm{pH}$. Limnol. Oceanogr., 27, 151-160.

Torres Boeger M.R.T. and Poulson M.E., 2003. Morphological adaptations and photosynthetic rates of amphibious Veronica anagallis-aquatica L. (Scrophulariaceae) under different flow regimes. Aquat. Bot., 75, 123-135.

Tóth V.R. and Herodek S., 2009. A simple incubation tank for photosynthesis measurements with six light intensities. Ann. Limnol. - Int. J. Lim., 45, 195-202.

Van T.K., Wheeler G.S. and Center T.D., 1999. Competition between Hydrilla verticillata and Vallisneria americana as influenced by soil fertility. Aquat. Bot., 62, 225-233. 